\title{
Dynamic model of phytoplankton growth and acclimation: responses of the balanced growth rate and the chlorophyll a: carbon ratio to light, nutrient-limitation and temperature
}

\author{
R. J. Geider ${ }^{1, *}$, H. L. MacIntyre ${ }^{2}$, T. M. Kana ${ }^{3}$ \\ ${ }^{1}$ Marine Biological Association of the UK, The Laboratory, Citadel Hill, Plymouth PL1 2PB, England \\ ${ }^{2}$ College of Marine Studies, University of Delaware, Lewes, Delaware 19958-1298, USA \\ ${ }^{3}$ Horn Point Environmental Laboratories, University of Maryland, Box 775, Cambridge, Maryland 21613-0775, USA
}

\begin{abstract}
Acclimation of the photosynthetic apparatus to changes of irradiance, temperature and nutrient availability, involving regulation of the chlorophyll acarbon ratio $(\theta)$, is a universal feature of all phytoplankton studied to date. We derive a dynamic regulatory model that predicts the dependencies of $\theta$ and growth rate $(\mu)$ on irradiance, daylength, temperature and nutrient availabilit.v. The model requires specification of 4 parameters to describe the light-dependencies of $\theta$ and $\mu$ under nutrient-saturating conditions at constant temperature. These are the maximum value of $\theta\left(\theta_{m}\right)$, the intial slope of the chl a-specific photosynthesis-light response curve $\left(\alpha^{\text {tht }}\right)$, the maximum carbon-specufic photosyn-

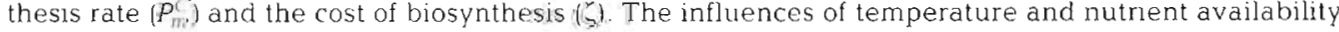
are accommodated through their effects on $P_{m}^{c}$. The temperature dependonce is described by the slope of an Arrhenius plot and the nutrient dependence is described through the half saturation constant $\left(K_{N}\right)$ of the Monod equation. Fidelity of the model results to empirical studies suggests that microalgal cells adjust $\theta$ in response to an imbalance between the rate of light absorption and the energy demands for photosynthesis and biosynthesis.
\end{abstract}

KEY WORDS: Chlorophyll a Chlorosis - Nutrient-limitation - Light Temperature Photoadaptation Photoacclimation. Phytoplankton.

\section{INTRODUCTION}

Documenting the spatial and temporal distributions of phytoplankton biomass is a necessary step in evaluating the role of the ocean in biogeochemical cycles (Longhurst et al. 1995) and in determining the longterm responses of coastal ecosystems to anthropogenic activity (Harding 1994). The most widely measured index of phytoplankton abundance is chlorophyll a (chl a) concentration, and a variety of techniques are available for measuring it directly. In addition, light absorption by phytoplankton allows remote sensing of chl a concentration from satellites and aircraft (Lewis

\footnotetext{
•E-mail: rdg@wpo.nerc.ac.uk
}

1992), and the in vivo fluorescence of chl a allows continuous determination of phytoplankton abundance by ship-based, aircraft and moored instruments (Falkowski \& Kiefer 1985). Data on the temporal and spatial distributions of chl a in coastal and open ocean waters is accumulating rapidly with increased use of these optical instruments.

Substitution of measurement of pigment concentration for direct cell counts in the 1930s (Harvey 1934) paved the way for the quantitative treatment of phytoplankton production dynamics (Mills 1989). Despite widespread measurement of chl a concentration, and the importance of these measurements in advancing our knowledge of marine primary productivity, chl $a$ is a poor measure of phytoplankton biomass (Strickland 1960, Cullen 1982). Chl $a$ is a small and variable com- 
ponent of phytoplankton biomass accounting for approximately 0.1 to $5 \%$ of phytoplankton organic matter (see Geider 1993). It is currently difficult, if not impossible, to translate the chl a distribution unambiguously into much more useful information on phytoplankton carbon or nitrogen distribution. Consequently, knowledge of the chl a:carbon ratio $(\theta)$ is essential for improving our understanding of the role of the ocean biota in the global carbon cycle, for estimating phytoplankton growth rates from measurements of ${ }^{14} \mathrm{CO}_{2}$ assimilation, for determining the food available to herbivores, and for assessing the contribution of phytoplankton to light attenuation.

The chl a:carbon ratio varies from $<0.01$ to $>0.1 \mathrm{~g}$ $\mathrm{g}^{-1}$ in phytoplankton cultures (Geider 1987, Geider 1993), and is expected to show an equally large range in nature. Chl a:carbon has typically been estimated for natural phytoplankton assemblages by regressing chl a concentration against particulate organic carbon concentration, although this technique has serious limitations (Banse 1977). Chl a:carbon can be measured during chla-labeling experiments (Redalje \& Laws 1981), but the technique employs samples that are isolated from the water column for periods of 12 to $24 \mathrm{~h}$ and is thus subject to the uncertainty associated with bottle effects. Finally, flow cytometry can provide information on the chl a to carbon ratio of individual cells using fluorescence and scattering signals ( $\mathrm{Li}$ et al. 1993, Campbell et al. 1994), although there are uncertainties due to variable chl a fluorescence yields and changes in the relationship between light scatter and carbon content (Stramski \& Reynolds 1993).

Fortunately, $\theta$ does not vary randomly. Rather it is highly regulated in response to irradiance, nutrient availability and temperature (Goldman 1980, Geider 1987, 1993, Langdon 1988a, b. Cloern et al. 1995). It is maximal at high temperatures $\left(25\right.$ to $\left.30^{\circ} \mathrm{C}\right)$ and low irradiances $\left(<20 \mu \mathrm{mol}\right.$ photons $\left.\mathrm{m}^{-2} \mathrm{~s}^{-1}\right)$ under nutrientreplete conditions and declines at high irradiances, especially at low temperature and under nutrientlimiting conditions. This paper presents a model for describing variations of growth rate $(\mu)$ and $\theta$ in microalgae under different conditions of irradiance, nutrient availability and temperature. The model is an extension of our previous dynamic description of photoacclimation (Geider et al. 1996) in which the ratio of chl a synthesis to photosynthesis is determined by a simple regulatory rule. That rule states that changes in pigmentation are determined by the ratio of the energy supply from light absorption and photosynthetic energy conversion to the energy demand for growth. The rule provides a metabolic feed-back that describes the stable intermediate pigment levels observed over a range of different stable environmental conditions.
Down regulation of $\theta$ at high irradiance occurs because the rate of light absorption exceeds the maximum capacity to assimilate photosynthate. Alternatively. temperature or restricted nutrient availability may constrain growth rate and thus reduce the demand for energy, leading in turn to a reduction in $\theta$.

In this paper we provide an analytical solution for the response of $\theta$ to irradiance in balanced growth based on the model presented by Geider et al. (1996). We provide an internally consistent and fully self-contained description of photosynthesis, growth and pigment content under nutrient-saturated conditions at constant temperature. That is, our model does not require specification of a growth function to derive pigment levels (or vice versa) as required prior to Geider et al. (1996). The effects of nutrient-limitation and temperature are incorporated into the model through the constraints that they impose on the light-saturated photosynthesis rate.

\section{THEORY}

Nutrient saturated growth. The response of photosynthesis to irradiance is commonly modeled as a photosynthesis-irradiance (PI) response curve (Jassby \& Platt 1976), which describes the biomass-specific rate of photosynthesis as a saturating function of irradiance. Although chl a is typically used as the measure of biomass, we have chosen to use particulate carbon because it reflects cellular energy content. Light-saturated photosynthesis is assumed to be proportional to organic carbon concentration (C). This is consistent with the relative independence of Rubisco from irradiance in nutrient-replete conditions (Sukenik et al. 1987 ) and the limited within-strain variability of the maximum carbon-specific photosynthesis rate $\left(P_{m}^{C}\right)$ with irradiance in many algae and cyanobacteria (Geider 1993). In contrast, light-limited photosynthesis is assumed to be proportional to the product of the chl a concentration and irradiance (i.e. we assume a constant chlorophyll-specific light absorption coefficient and a constant quantum yield at low light). This is consistent with observations that the chl a-specific initial slope of the PI curve $\left(\alpha^{c h}\right)$ shows limited intraspecific variability (Geider 1993).

The organic carbon-specific photosynthesis rate $\left(P^{C}\right)$ is expressed as a function of the irradiance ( $I$ ) and the chl a:carbon ratio $(\theta)$ as follows:

$$
p^{C}=P_{m}^{C}\left[1-\exp \left(\frac{-\alpha^{c h l} I \theta}{P_{m}^{C}}\right)\right]
$$

where $P^{C}$ is the carbon-specific photosynthesis rate, $\alpha^{c h l}$ is the initial slope of the PI curve normalized to chl $a$, and $P_{m}^{C}$ is the light-saturated rate of photosynthe- 
sis normalized to carbon. (See Table 1 for a summary of symbols.) This treatinent of the PI response has many similarities to the qualitative consideration of photoacclimation given in Chan (1978). Note that Eq. (1) is a static description of instantaneous achieved photosynthesis at a given irradiance, constrained by $P_{m}^{C}$ and a constant quantum efficiency of photosynthesis. The question at hand is how this instantaneous response effects a change in the chl a to carbon ratio.

To describe photoacclimation, we assume that changes in $\theta$ arise from variations in the relative rates of net chl a synthesis and net carbon accumulation. The net rate of carbon accumulation $(d C / d t)$ is given by the difference between the rates of photosynthesis and respiration (Eq. 2). Similarly, the net rate of chl a accumulation $(d c h l / d t)$ is given by the difference between the rates of chl a synthesis and degradation (Eq. 3)

$$
\begin{gathered}
\frac{d C}{d t}=p^{C} C-R^{C} C \\
\frac{d c h l}{d t}=p_{c h l} P^{C} C-R^{c h l} C h l
\end{gathered}
$$

where $R^{C}$ and $R^{c h l}$ are the degradation rate constants for carbon and chl $a$, and $\rho_{c h l}$ is the ratio of chl a synthesis to carbon fixation. We neglect excretion of dissolved organic matter, although this could be considered as an additional loss term in Eq. (2). Following Geider \& Platt (1986), we treat the gross chl a synthesis rate as the product of the rate of photosynthesis $\left(P^{C} C\right)$ and the proportion of photosynthate that is directed to chlorophyll biosynthesis $\left(\rho_{c h l}\right)$. We assume that $\rho_{c h l}$ is regulated by the ratio of achieved to maximum poten- tial photosynthesis:

$$
\rho_{c h l}=\theta_{m}\left(\frac{P^{C} C}{\alpha^{c h /} I c h l}\right)=\theta_{m}\left(\frac{P^{C}}{\alpha^{c h l} I \theta}\right)
$$

where $\theta_{m}$ is the maximum chl a to carbon ratio observed in cells acclimated to extremely low light. We define the phrase 'regulatory ratio' to be the term $P^{c} / \alpha^{c h l} I \theta$. In studying the regulatory ratio, note that the numerator is ultimately constrained by $P_{m}^{C}$ (see Eq. 1), whereas the denominator is effectively unconstrained because of the inclusion of $I$. Hence, $\rho_{c h l}$ declines when the instantaneous light harvesting capacity (i.e. $\alpha^{c h l} I \theta$ ) exceeds the instantaneous photosynthesis rate.

Eqs. (1) to (4) can be solved for the condition of balanced growth to yield the following relation between $\theta$ and $I$ (see Appendix 1 for the derivation):

$$
\theta=\frac{\theta_{m}}{1+\left(\frac{\theta_{m} \alpha^{c h l} I}{2 P_{m}^{C}}\right)}=\frac{\theta_{m}}{1+\left(\frac{I}{2 K_{l}}\right)}
$$

where $K_{I}=P_{m}^{C} /\left(\alpha^{c h l} \theta_{m}\right)$. Thus, $\theta$ is inversely related to irradiance, declining from a maximum value of $\theta_{m}$ at very low irradiance. The decline of $\theta$ with increasing irradiance depends on the ratio of the chl a-specific initial slope $\left(\alpha^{\mathrm{ch} h}\right)$ to the carbon-specific light-saturated photosynthesis rate $\left(P_{m}^{C}\right)$. Eq. (5) predicts a linear relationship of the carbon:chl a ratio (i.e. $1 / \theta$ ) to irradiance, as has been extensively documented in phytoplankton (Geider 1987, Kana \& Glibert 1987a).

\begin{tabular}{|c|c|c|}
\hline Symbol & Definition & Units \\
\hline$\alpha^{c h t}$ & Chl a-specific initial slope of the photosynthesis-light curve & 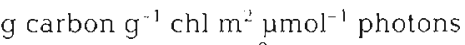 \\
\hline C & Organic carbon concentration & $\mathrm{g} \mathrm{m}^{-3}$ \\
\hline$c h l$ & Chl a concentration & $\mathrm{g} \mathrm{m}$ \\
\hline$D$ & Photoperiod duration & dimensionless \\
\hline$E_{d}$ & Activation energy & $\mathrm{J} \mathrm{mol}^{-1}$ \\
\hline$E_{\mathrm{d}} / R$ & Slope of the Arrhenius plot of the temperature dependence of metabolic rate & $\mathrm{K}$ \\
\hline$I_{k}$ & Saturation parameter for the photosynthesis-irradiance curve, $P_{m}^{c h l} / \alpha^{c h l}$ & umol photons $\mathrm{m}^{-2} \mathrm{~s}^{-1}$ \\
\hline$K_{1}$ & Saturation parameter for the growth-irradiance curve, $P_{m}^{C} / \alpha^{c h l} \theta_{\mathrm{m}}$ & umol photons $\mathrm{m}^{-2} \mathrm{~s}^{-1}$ \\
\hline$K_{N}$ & Half saturation constant of the Monod equation & $\mu \mathrm{M}$ \\
\hline$\mu$ & Growth rate & $s^{-1}$ \\
\hline$\mu_{m}$ & Maximum growth rate & $\mathrm{s}^{-1}$ \\
\hline$p^{c}$ & Carbon-specific photosynthesis rate & $s^{-1}$ \\
\hline$P_{m !}^{C}$ & Carbon-specific, light-saturated photosynthesis rate & $s^{-1}$ \\
\hline$P_{M \lambda \lambda}^{C}$ & Maximum photosynthesis rate at the reference temperature & $s^{-1}$ \\
\hline$P_{m}^{c h l}$ & Chlorophyll a-specific, light-saturated photosynthesis rate & 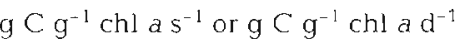 \\
\hline$R$ & Universal gas constant & $8.3 \mathrm{~J} \mathrm{~mol}^{-1} \mathrm{~K}^{-1}$ \\
\hline$T$ & Temperature & $\mathrm{K}$ \\
\hline$T_{\text {ref }}$ & Reference temperature $(293 \mathrm{~K})$ & $\mathrm{K}$ \\
\hline$\theta$ & Chl a:carbon ratio & $g \mathrm{chl}$ a $\mathrm{g}^{-1} \mathrm{C}$ \\
\hline$\theta_{n 2}$ & Maximum chl a:carbon ratio & $\mathrm{g} \mathrm{chl} \mathrm{g} \mathrm{g}^{-1} \mathrm{C}$ \\
\hline$\zeta$ & Cost of biosynthesis & dimensionless \\
\hline
\end{tabular}

The parameter $K_{l}$ (see Eq. 5) provides a measure of the irradiance at which grow th becomes light-saturated. It is

Table 1. Definitions of terms in a photoadaptation model 
approximately equal to the irradiance at which the initial slope of the growth versus irradiance curve intercepts the light-saturated growth rate. Note that $K_{i}$ differs from $I_{k}$, the light-saturation parameter for photosynthesis. In our model, $I_{k}$ is a variable determined by the ratio of chl a-specific light-saturated photosynthesis to the chl a-specific initial slope of the PI curve:

$$
I_{k}=\frac{P_{m i}^{c h l}}{\alpha^{c h l}}=\frac{P_{m}^{c}}{\alpha^{c h l} \theta}
$$

$K_{l}$ can be considered as the lower limit on $I_{k}$

Growth rate $(\mu)$ is by definition equal to the carbonspecific rate of change of carbon concentration, $1 / C(d C / d t)$. Thus, $\mu$ can be obtained from Eqs. (1) and (2) as follows:

$$
\mu=P_{m !}^{C}\left[1-\exp \left(\frac{-\alpha^{c h l} I \theta}{P_{m}^{C}}\right)\right]-R^{C}
$$

We assume that the respiration rate, $R^{C}$, is directly proportional to the growth rate with zero respiration rate at zero growth rate:

$$
R^{C}=\mu \zeta
$$

where $\zeta$ is the cost of biosynthesis. The value of $\zeta$ can be calculated from the energetic cost of synthesizing proteins and lipids using carbohydrates as a source of carbon skeletons (Penning de Vries et al. 1974, Geider 1992). Substituting Eq. (8) into Eq. (7) yields:

$$
\mu=\frac{P_{m}^{C}}{1+\zeta}\left[1-\exp \left(\frac{-\alpha^{c h l} I \theta}{P_{n}^{C}}\right)\right]
$$

Eq. (9) holds for continuous illumination. To account for variations in the photoperiod, we make the simplifying assumption that the maximum achievable growth rate is proportional to the duration of the photoperiod (Sakshaug et al. 1989).

$$
\mu=\frac{D P_{m}^{c}}{1+\zeta}\left[1-\exp \left(\frac{-\alpha^{c h l} I \theta}{P_{m}^{C}}\right)\right]
$$

where $D$ is the proportion of the day that is illuminated (e.g, for a 6 h light: 18 h dark cycle, $D=0.25$ ). Eq. (10) can also be rearranged to obtain a description of $\theta$ as a function of $\mu$ and $I$.

$$
\theta=-\frac{P_{i n}^{C}}{\alpha^{c h l} I} \ln \left[1-\frac{\mu(1+\zeta)}{D P_{m}^{C}}\right]
$$

Thus, a complete description of $\mu$ and $\theta$ as a function of irradiance can be obtained by specifying 4 constants. These are the maximum chl a to carbon ratio observed at low light $\left(\theta_{m}\right)$; the chl a-specific initial slope of the photosynthesis-light response curve $\left(\alpha^{c h l}\right)$; the carbon-specific maximum photosynthesis rate $\left(P_{m}^{C}\right)$; and the cost of biosynthesis $(\zeta)$. We assume that these parameters are independent of growth irradiance under nutrient-replete conditions.
Irradiance-dependence of $\mu$ and $\theta$ under nutrientreplete conditions and constant temperature. If we select various values of $P_{m}^{C} \alpha^{c h l}$ and $\theta_{m}$, then considerable variability can be imposed on a plot of the carbonspecific photosynthesis rate, $P^{C}$, against irradiance, $I$ (Fig 1A). Scatter is reduced when $P^{C}$ is plotted against the maximum potential rate of light energy conversion (Fig. 1B), where both photosynthesis and light energy conversion are expressed as carbonspecific rates with units of inverse time. The initial slope of a plot of $P^{C}$ versus the product $\alpha^{c h l} \theta I$ at low light is unity. Finally, we note that a single curve (Fig. 1C) describes the behavior of photosynthesis (i.e. $P^{C / P_{m}^{C}}$ ) as a function of $\alpha^{c h l} \theta_{m} / / P_{m}^{C}=I / K_{l}$. For Fig $1 \mathrm{C}$, we have made $P^{C}$ nondimensional by normalizing to $p_{m}^{C}$ and we made irradiance nondimensional by dividing by $K_{1}$. Fig $1 \mathrm{C}$ shows that our model requires that all species (as defined by the combination of parameter. values) operate in essentially the same way, despite exhibiting very different growth rate versus irradiance response curves. The critical factor is the level of irradiance relative to that which saturates growth. Significantly, the analytical solution (Eq 5 ) does not allow $P^{C}$ to attain its maximum value $\left(P_{m}^{C}\right)$ under conditions of balanced growth because of down regulation of $\theta$ (Eq. 5). The model predicts that the photosynthetic rate of cells in balanced growth will always be less than the light-saturated maximum photosynthesis rate. Note that this relationship holds for all values of the respiration constant $\zeta$. The dependence of $\mu$ on $I / K_{I}$ for various values of $\zeta(0<\zeta<0.2)$ is shown in Fig. 1C. For the hypothetical cell with zero respiration (i.e. $\zeta=0$ ), growth and photosynthesis have exactly the same dependence on irradiance.

Effects of temperature and nutrient-limitation on growth. We assume that nutrient-limitation and temperature affect phytoplankton physiology only by imposing a limit on the light-saturated photosynthesis rate. The temperature dependence of $p_{m}^{c}$ is treated as an Arrhenius equation (Li 1980), and nutrient-limitation of $P_{m}^{C}$ is described by the Monod equation (Morel 1987). Thus, $P_{m}^{C}$ is considered to be a multiplicative function of temperature and nutrient availability as follows:

$$
P_{m}^{C}(T, N)=P_{M A x}^{C} \frac{N}{N+K_{N}} \exp \left[\frac{-E_{a}}{R}\left(\frac{1}{T}-\frac{1}{T_{\text {ret }}}\right)\right]
$$

where $P_{m}^{C}(T, N)$ is the maximum photosynthesis rate allowed by a given temperature and nutrient concentration, $T$ denotes temperature, $T_{\text {ref }}$ is a reference temperature of $293 \mathrm{~K}, P_{M A X}^{C}$ is the reference value of $P_{m}^{C}$ at $T_{\text {rel }}$ under nutrient-replete conditions, $N$ denotes nutrient concentration, $K_{N}$ is the half saturation constant for growth and $E_{d} / R$ is the slope of an Arrhenius plot. Thus, once the 4 parameters governing nutrient- 

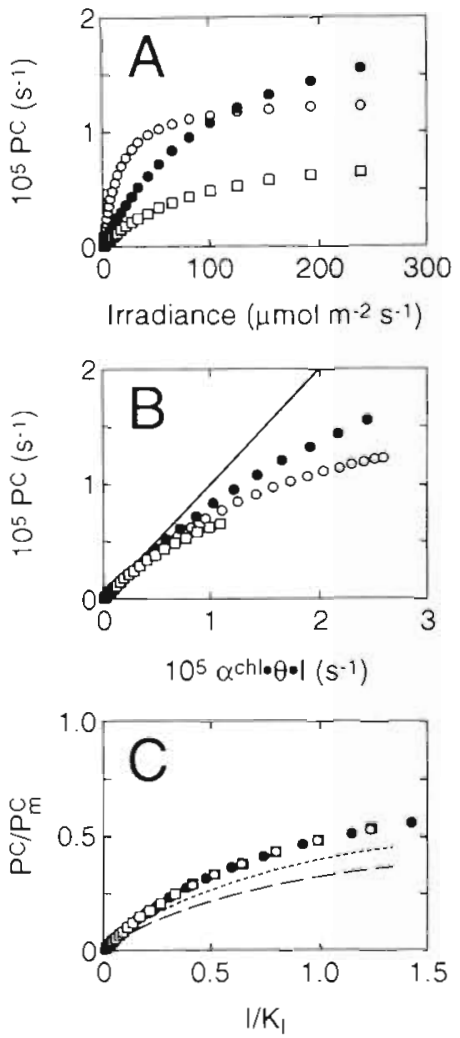

Fig. 1 Variation of carbon-specific photosynthetic rates with irradiance. (A) Net acclimated photosynthetic rate, $P^{\prime}$, as a function of irradiance for hypothetical microalgae with varous values of $P_{m}^{C}\left(1.0\right.$ to $\left.2.5 \times 10^{-5} \mathrm{~s}^{-1}\right), \alpha^{\text {cht }}\left(1.0\right.$ to $2.0 \times 10^{-5} \mathrm{~g} \mathrm{C}$ $\mathrm{g}^{-1} \mathrm{Chl} \mu \mathrm{mol}^{-1}$ photons $\left.\mathrm{m}^{2}\right)$ and $\theta\left(0.01\right.$ to $\left.0.04 \mathrm{~g} \mathrm{chl} \mathrm{g}^{-1} \mathrm{C}\right)$. (B) Acclimated photosynthesis rate, $p^{c}$, as a function of the maximum potential rate of light absorbtion and photosynthetic energy conversion (expressed as $\alpha^{c h} \theta I$ ) for the hypothetical algae in (A). The solid line is the 1:1 relationship. (C) Effect of variations in the cost of biosynthesis, $\zeta$, on the relationship between normalized growth rate, $P^{C} / P_{m}^{C}$ and irradiance for the hypothetical algae in $(A)$ and $(B)$. Irradiance is expressed as $I / K_{1}\left\{=\alpha^{c h l} \theta_{m} I / P_{m}^{C}\right)$. Dotted line: $\zeta=0.1$. Dashed line: $\zeta=0.2$

replete growth, at constant temperature have been specified, it is necessary to add only 2 additional parameters to describe the nutrient and temperature dependencies of $\mu$ and $\theta$. These parameters are the slope of the Arrhenius relation $\left(E_{d} / R\right)$ and the halfsaturation constant for nutrient uptake $\left(K_{N}\right)$.

Light, nutrient and temperature dependence of $\boldsymbol{\theta}$. The model requires that $\theta$ decline as $\mu$ increases under nutrient-replete conditions. The upper curve (solid symbols) in Fig. 2A shows the dependence of $\theta$ on relative growth rate for cells acclimated to a range of irradiances under nutrient-replete growth conditions. This curve sets an upper limit for $\theta$ that can be obtained at a given temperature. Note that $P_{m}^{C}$ exceeds the maximum growth rate by about 15 to $20 \%$. The lower set of
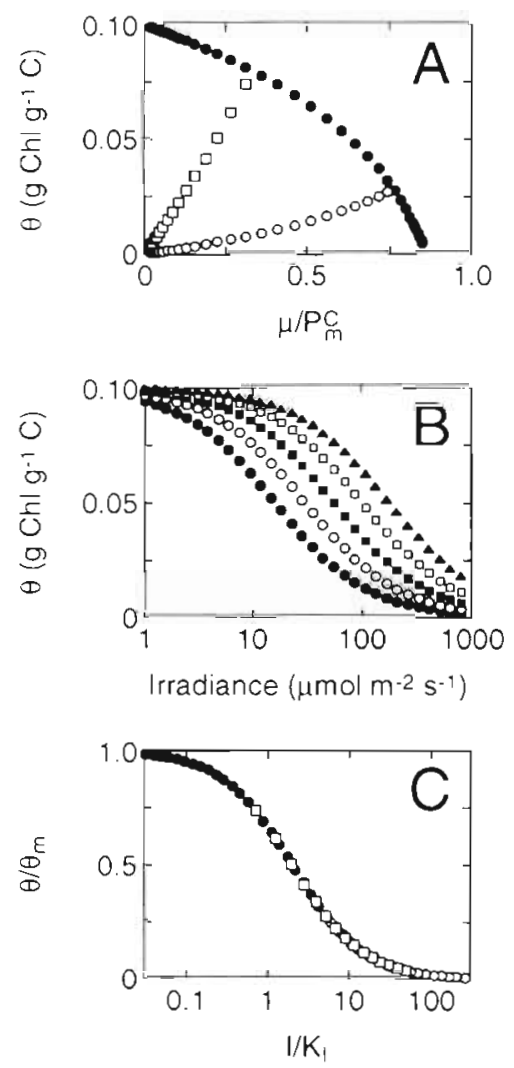

Fig. 2. Variation of the chl a:carbon ratio with nutrient limitation and temperature. (A) $\mathrm{Chl}: \mathrm{C}$ ratio, $\theta$, as a function of standardized growth rate, $\mu / P_{m}^{C}$. Data are for a hypothetical alga grown at 1 to $2000 \mu \mathrm{mol} \mathrm{m} \mathrm{m}^{-2} \mathrm{~s}^{-1}$ under nutrient replete conditions $(\bullet)$ and at 25 and $250 \mu \mathrm{mol} \mathrm{m} \mathrm{m}^{-1} \mathrm{~s}^{-1}\left(=0.5 K_{i}\right.$ and $5 K_{f}$ ) under nutrient-limited conditions $(\square$ and $O)$. Parameter values: $P_{m}^{C}=2.5 \times 10^{-5} \mathrm{~s}^{-1} ; \mu_{m}=2.25 \times 10^{-5} \mathrm{~s}^{-1} ; \alpha^{c h t}=0.5 \times 10^{-5} \mathrm{~g}$ $\mathrm{C} \mathrm{g}^{-1}$ chl $\mu \mathrm{mol}^{-1}$ photons $\mathrm{s}^{-1} \mathrm{~m}^{2} ; \theta_{m}=0.1 \mathrm{~g} \mathrm{chl} \mathrm{g}^{-1} \mathrm{C}$. (B) Chl: $\mathrm{C}$ ratio, $\theta$ as a function of irradiance at 5 temperatures $(273 \mathrm{~K}$; $0.278 \mathrm{~K} ; \mathbf{\square}, 283 \mathrm{~K}_{i} \square, 288 \mathrm{~K}_{i} \mathbf{\Delta}, 293 \mathrm{~K}$ ) for a hypothetical alga. Parameter values are as for $(\mathrm{A})$ and $E_{\alpha} / R=10^{4} \mathrm{~K}$ (C) Standardized chl C ratio, $\theta / \theta_{m}$, as a function of irradiance, $I / K_{l}$, for

the nutrient-replete and nutrient-limited cultures in (A)

curves (open symbols) in Fig. 2A shows the results for nutrient-limited growth at irradiances of 25 and $250 \mu \mathrm{mol}$ photons $\mathrm{m}^{-2} \mathrm{~s}^{-1}$ (equivalent to $0.5 K_{I}$ and $5 K_{I}$ ). These curves are predictions of the results of chemostat experiments operated at different dilution rates (i.e. different relative growth rates).

The temperature dependence of $\theta$ is best illustrated by examining superimposed plots of $\theta$ versus irradiance (Fig. 2B). Under nutrient replete conditions, $\theta$ is inversely related to both irradiance and temperature (Fig. 2B). At any given irradiance, $\theta$ declines with decreasing temperature. Finally, note that the light, temperature and nutrient dependencies of $\theta$ collapse on to a single curve when $\theta / \theta_{m}$ is plotted versus $I / K_{I}$ (Fig 2C). 


\section{DATA, DATA ANALYSIS AND RESULTS}

\section{Nutrient-replete conditions at constant temperature}

Observations of growth rate $(\mu)$ and the chl a:carbon ratio $(\theta)$ as functions of irradiance $(I)$ were obtained from the literature. A variety of techniques were used to measure chl a and organic carbon, but no attempt was made to correct for any systematic variations that may have arisen. Irradiance was measured by scalar and cosine detectors in light fields that undoubtedly differed in geometry. Again, there was no attempt to correct for systematic variations.

We used a least squares routine to fit observed values of growth rate to the function

$$
\mu=a_{1} D\left[1-\exp \left(-a_{2} \theta I\right)\right]
$$

using the observed values of $\theta$ and $I$. Note that the dependent variable $\mu$ is a function of 2 variables ( $I$ and $\theta) . I$ is the only independent variable in phytoplankton growth studies. $\theta$, like $\mu$, is a dependent variable. We fit observations of $1 / \theta$ to the equation

$$
\frac{1}{\theta}=b_{1}+b_{2} I
$$

This function has the advantage of fitting one dependent variable $(\theta)$ to one independent variable $(I)$.

The following empirical equation was fitted to observations of $\mu$ :

$$
\mu=\mu_{m}\left[1-\frac{I}{K_{l}}\right]
$$

where $\mu_{m}$ is the maximum growth rate and $K_{I}$ is the light-saturation parameter. Inspection shows that the following identities should hold:

$$
\begin{gathered}
a_{1}=\frac{p_{m}^{C}}{1+\zeta} \\
\frac{b_{1}}{a_{2}}=\frac{b_{1}}{2 b_{2}}=K_{I}
\end{gathered}
$$

Thus, we have an estimate of $\theta_{m}$ (i.e. $1 / b_{1}$ ), an estimate of $P_{m}^{C} /(1+\zeta)$, and 3 estimates of $K_{r}$. We cannot obtain independent estimates of $\alpha^{c h l}, P_{m}^{C}$ and $\zeta$. However, given an estimate for $\zeta$, we obtain $P_{m}^{C}$.

The model could be adequately fit to the data even under the assumption that $\zeta=0$. This is convenient for 2 reasons. First, it is difficult, if not impossible, to obtain a direct measurement of $\zeta$ (see Geider 1992 for a review). Second, many of the data sets have a limited number of observations and the ability to simplify the model by eliminating one of the fitted parameters gives greater confidence in the procedure. Thus, it was only necessary to determine the values of 3 parameters: $P_{m}^{C}, K_{l}$ and $\theta_{m}$ the value of $\alpha^{c h l}$ can be calculated from the values of these parameters. Predictions of the
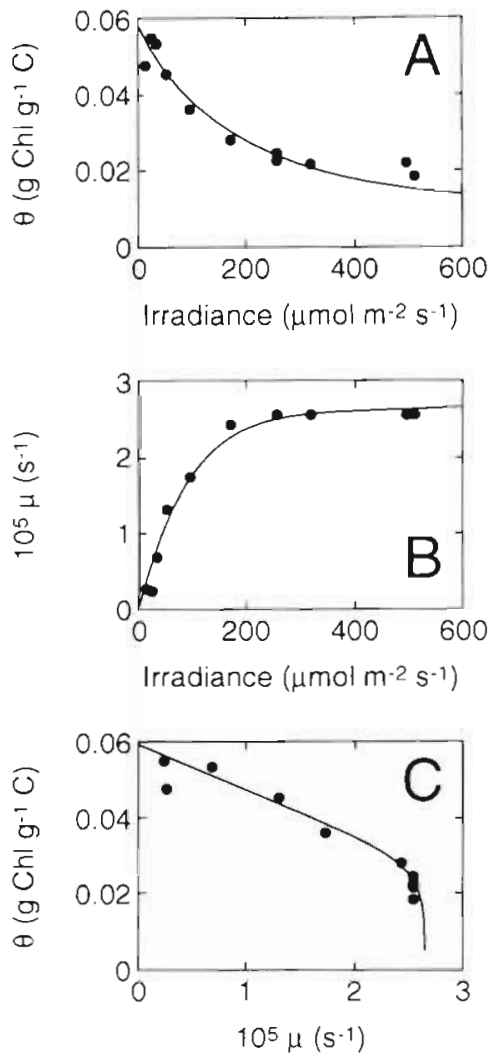

Fig. 3. Comparison of model fits (lines) with data (9) for nutrient-replete cultures of Thalassiosira pseudoana (Geider 1984). (A) ChI:C ratio, $\theta$, as a function of irradiance. The solid line is the fit to Eq. (14). (B) Growth rate, $\mu$, as a function of irradiance. The solid line is the fit to Eq. (15). (C) Chl:C ratio, $\theta$, as a function of growth rate, $\mu$. The solid line is the model's prediction, based on irradiance

irradiance dependencies of $\mu$ and $\theta$ from the parameters given by fitting to Eqs. (13) to (15) are in good agreement with observations (Fig. 3).

Observations for 15 algal and cyanobacterial species were used to obtain estimates of parameter values for the photoacclimation model (Table 2). Some general patterns emerge despite the wide range of techniques used to measure chl a and carbon concentrations and the differences in light sources and optical geometries amongst the investigations conducted in different laboratories. In general, cyanobacteria and dinoflagellates are characterized by low values of $\theta_{m}$ and diatoms by high values. The highest values of $\alpha^{\text {chl }}$ were observed in the cyanobacteria, probably because cyanobacteria have high concentrations of accessory light harvesting pigments relative to chl $a$. The lowest values of $p_{m}^{C}$ were observed in the dinoflagellates, consistent with the low resource-saturated growth rates typical of this taxon. The model predicts that fully acclimated phytoplankton grow at somewhat less than light-saturation: $P_{m}^{C}$ was consistently about $20 \%$ 


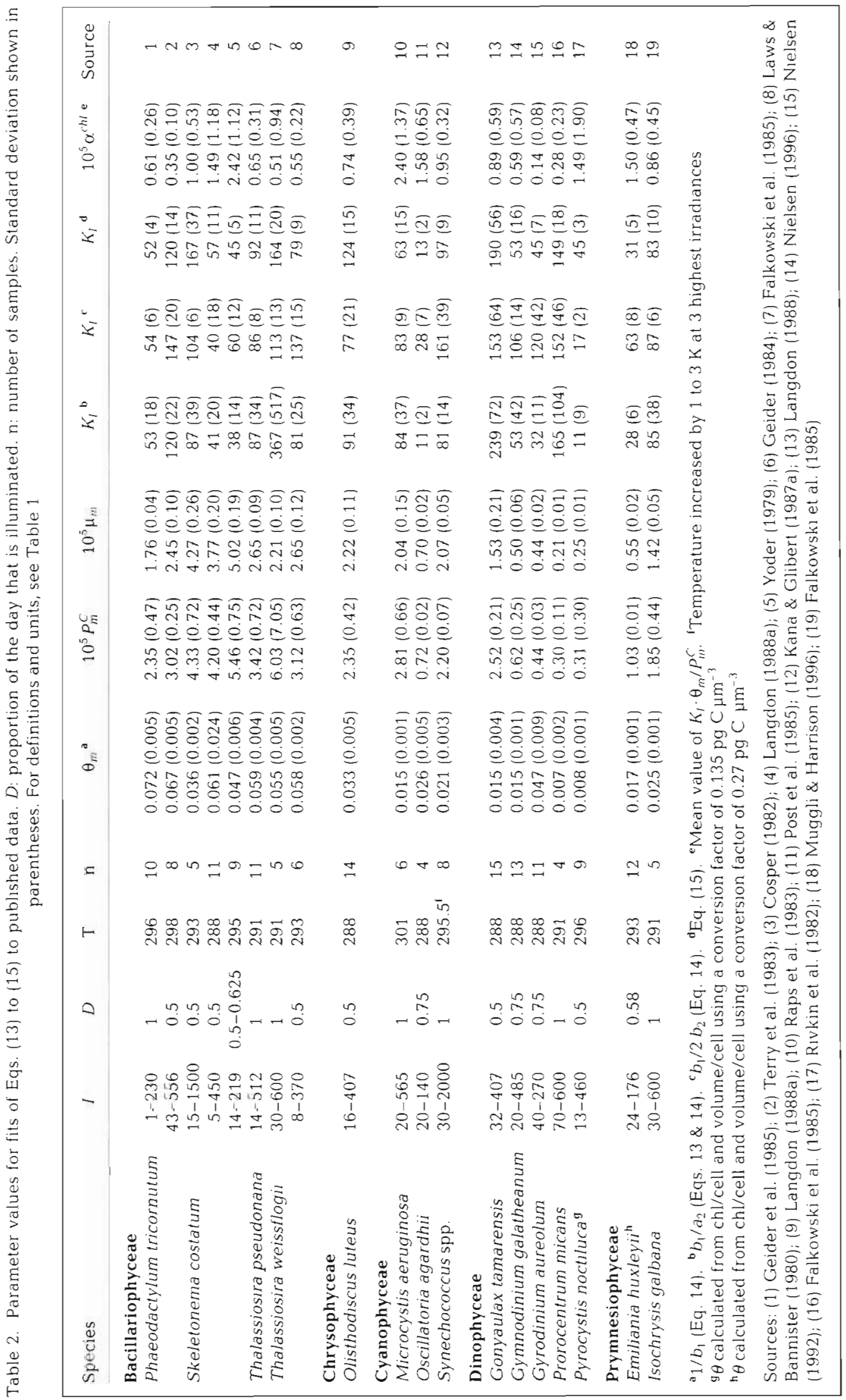



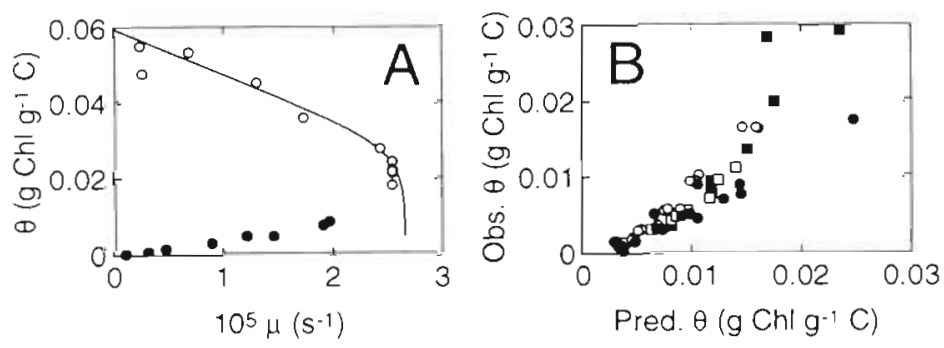

Fig. 4. Companson of model predictions with observed data under nutrient-limited conditions. (A) Chl:C ratio, $\theta$, as a function of growth rate, $\mu$, for cultures of Thalassiosira pseudonana (Gelder 1984). Cultures were grown under nutrient-replete conditions between 14 and $512 \mu \mathrm{mol} \mathrm{m} \mathrm{m}^{-2} \mathrm{~s}^{-1}(\mathrm{O})$ and under nutrient lumited conditions between 460 and $560 \mu \mathrm{mol} \mathrm{m} \mathrm{m}^{-2} \mathrm{~s}^{-1}(\bullet)$. The solid line is the model fit to the nutrientreplete data (cf. Fig. 3C). (B) Observed values of $\theta$ under nutrient-limitation vs values predicted from the growth rate and the parameters of the model fit to nutrient-replete data (Table 2) for $T$ pseudonana ( Geider 1984; $\mathrm{n}=16, \mathrm{R}^{2}=0.89$ ), $T$ weissflogii $(\mathrm{O}$, Laws \& Bannister 1980; $\left.\mathrm{n}=15, \mathrm{R}^{2}=0.88\right)$, Phasedactylum tricornutum ( $\mathbf{\square}$, Terry et al. 1983; $\mathrm{n}=10, \mathrm{R}^{2}=0.75$ ), and Isochrysis galbana ( $\square$, Herzig \& Falkowski 1989, based on fit to data of Falkowski et al. 1985; $n=9, R^{2}=0.87$ )
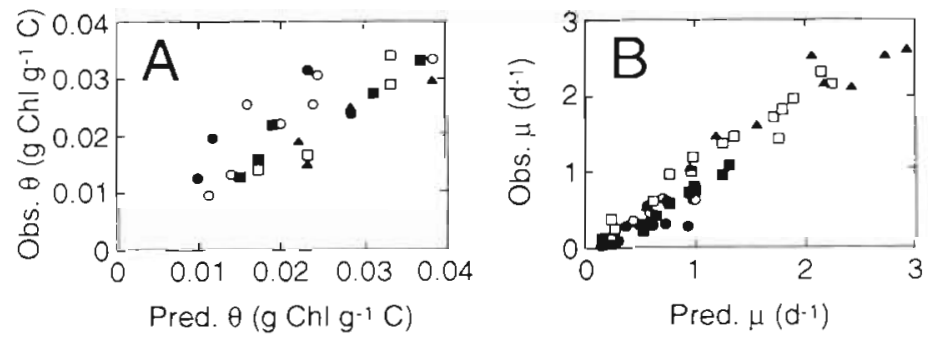

Fig. 5. Comparison of model predıctions with observed data at different growth temperatures. (A) Observed values of $\theta$ vs values predicted from irradiance for Skeletonema costatum (Yoder 1979; $\mathrm{n}=23, \mathrm{R}^{2}=$ $0.64)$. Cultures were grown at 5 temperatures $\left(\bullet, 273 \mathrm{~K}_{i} \mathrm{O}, 278 \mathrm{~K}\right.$. , $283 \mathrm{~K}_{i}[\mathrm{c}, 289 \mathrm{~K}$ and $\mathbf{\Delta}, 295 \mathrm{~K}$ ). (B) Observed values of $\mu$ vs values predicted from irradiance for $S$. costatum (Yoder 1979; $n=51, R^{2}=0.90$ ). Symbols as in (A). Predictions were based on the fitted value of $\theta_{n}$ at $295 \mathrm{~K}$ (Table 2): the mean value of $\alpha^{\text {chl }}$ at 273 to $295 \mathrm{~K}[2.05( \pm 0.27) \times$ $10^{-5} \mathrm{~g} \mathrm{C} \mathrm{g}^{-1} \mathrm{chl} \mu \mathrm{mol}^{-1}$ photons $\mathrm{m}^{2}$ ); and the temperature-sensitive value of $P_{m}^{c}$, calculated from the value at $295 \mathrm{~K}$ (Table 2 ) and the fitted value of $E_{d} / R\left[4475( \pm 1271) \times 10^{4} \mathrm{~K}\right)$

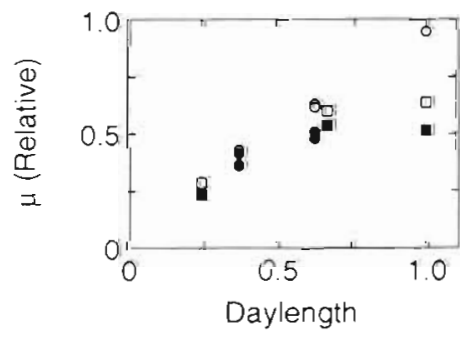

Fig. 6. Relationship betwen relative growth rate and daylength in Skeletonema costatum ( Verity 1982), Emiliana huxleyi (ㅁ, Paasche 1967) and Nitzschia turgidula (ם, Paasche 1968). The relative growth rate was calculated by normalizing to the rate at the shortest photoperiod and scaling to the duration of the photoperiod greater than $\mu_{m}$. This is consistent with a direct comparison of the light-saturated growth rate $\left(\mu_{m}\right)$ and light-saturated photosynthesis rate $\left(P_{m}^{C}\right)$ at $\mu_{m 1}$ (Geider 1993).

\section{Nutrient dependence}

To the best of our knowledge, there are no studies that provide observations to test the dependence of $\theta$ on nutrient concentration directly. In practice, $\mu$ is an independent variable controlled by dilution rate in nutrientlimited chemostat cultures and $\theta$ is typically reported as a function of $\mu$. Published observations of $\mu$ and $\theta$ under nutrient-limited conditions are available for 4 of the organisms for which we estimated $P_{m}^{c}, \alpha^{c h l}$ and $\theta_{m}$ for the nutrient-replete conditions. The parameter values obtained in the previous section were used in conjunction with the reported relative growth rates $\left(\mu / \mu_{m}\right)$ and irradiance to predict $\theta$ for the nutrient-limited cultures (Fig 4B). Thus, variations of $\theta$ under nutrient-limited conditions can be accounted for by assuming that the light-saturated photasynthesis rate covaries with the nutrient-Iimited growth rate.

\section{Temperature dependence}

The ability of the model to describe the temperature dependence of $\mu$ and $\theta$ was examined using a data set for Skeletonema costatum (Yoder 1979). Fifty-two measurements of $\mu$ and 24 measurements of $\theta$ are available for nutrient-replete cultures grown at temperatures of $0,5,10,16$ and $22^{\circ} \mathrm{C}$ on $9: 15,12: 12$ and $15: 9 \mathrm{~h}$ light:dark cycles over irradiances ranging from $<10$ to $220 \mu \mathrm{mol}$ photons $\mathrm{m}^{-2} \mathrm{~s}^{-1}$ There is good agreement between observed and predicted values of $\mu$ and $\theta$ (Fig 5A, B). The Arrhenius coefficient was $4475 \pm 1271 \mathrm{~K}$.

\section{DISCUSSION}

\section{Mechanisms of acclimation}

Variation of $\theta$ is one of the most consistent manifestations of photoacclimation, although accessory pigment composition, the abundance of photosynthetic proteins, PI curve parameters and the coupling of light absorption to electron transfer also vary (Falkowski \& La Roche 1991). Reduction of pigment content under 
high irradiance allows algae to reduce the rate of energy supplied by light harvesting, in order to bring light harvesting into balance with energy demands for carbon fixation and growth (Kana \& Glibert 1987a, b. Kiefer 1993). The biological 'light meter' that provides the signal for photoacclimation is believed to reside in the photosynthetic electron transfer chain. Specifically, the oxidation-reduction state of the plastoquinone pool appears to provide the primary signal leading to changes in the synthesis of light harvesting complex proteins (Escoubas et al. 1995)

Our model accounts for photoacclimation by defining a regulatory ratio as the ratio of carbon-specific photosynthesis divided by the linear extrapolation of the carbon-specific initial slope of the photosynthesisirradiance curve to ambient irradiance (i.e. $P C / \alpha^{c h l} I \theta$ ) This ratio parameterizes the balance between energy demand and supply, and can be thought of as an index of the redox state of the plastoquinone pool. The carbon-specific rate of photosynthesis $\left(P^{C}\right)$ is proportional to the rate at which electrons are drawn out of the photosynthetic electron transfer chain by the photosynthetic carbon reduction cycle. In contrast, the linear extrapolation of the initial slope of the PI curve $\left(\alpha^{c h l} / \theta\right)$ provides a measure of the supply of excitation energy to photosystem II The regulatory ratio approaches 1.0 at low irradiance, and declines as irradiance increases. This occurs because $P^{C}$ is a saturating function of irradiance but $\left(\alpha^{(h)} \theta I\right)$ increases linearly with irradiance. Similarly, plastoquinone is expected to be fully oxidized at low light and to become increasingly reduced as irradiance increases

Reductions in light-saturated growth rate due to nutrient-limitation or low temperature are expected to reduce the rate of electron flow out of photosystem II and thus reduce $P^{r}$. Acclimation of pigment content under these conditions should mimic acclimation to high irradiance (Maxwell et al. 1994). Our model assumes that the carbon-specific light-saturated photosynthesis rate $\left(P_{m}^{C}\right)$ is independent of irradiance under nutrient-replete conditions at constant temperature (Geider \& Platt 1986). Low nutrient availability or low temperature act exclusively by reducing $P_{m}^{C}$, and a simple regulatory rule (parameterized by $\rho_{c h i}$ in Eq. 3) provides predictions of compensating reductions in $\theta$. These assumptions allow us to account for much of the variability of $\theta$ over a range of temperatures and nutrient-limited growth rates (Figs. $4 \& 5$ ).

\section{Assumptions, deviations and limitations}

Deviations between predictions and observations may arise from limitations in the model or limitations in the available data. We made several assumptions that may limit the accuracy of our model. In this section we outline some of the limitations and refer the reader to additional sources of information, although it is not our intent to consider these limitations exhaustively.

First, we assumed that the chlorophyll-specific initial slope of the PI curve $\left(\alpha^{c h l}\right)$ is constant under all conditions of irradiance, temperature and nutrient-limitation. Reductions of $\alpha^{c h l}$ at high irradiance, low temperature or nutrient-limitation may arise because of reductions in the quantum efficiency of photosynthesis associated with accumulation of photoinhibitory damage or reversible down regulation of exciton transfer from the light-harvesting antennae to the reaction centers (Kolber et al. 1988, Herzig \& Falkowski 1989) To treat this phenomenon requires a mechanistic model of photoinhibition. In many instances, reduced quantum efficiency is balanced by increased light absorption due to a reduction of the package effect in chlorotic cells (Berner et al. 1989). Overall, $\alpha^{\text {chl }}$ varies by up to a factor of 2 within a species with changes in environmental variables, although it does vary more amongst species (see Geider 1993 for a review).

Second, we assumed that $P_{m}^{C}$ is independent of irradiance. Whereas $P_{m}^{c h l}$ may increase 10 -fold between irradiances of $<10$ and $>1000 \mu \mathrm{mol}$ photons $\mathrm{m}^{-2} \mathrm{~s}^{-1}, P_{m}^{C}$ typically varies less than 2 -fold (Geider 1993). Where it varies, $P_{n}^{c}$ does not increase monotonically with growth irradiance. Rather, it shows a maximum value at intermediate irradiances (Kana \& Glibert 1987b. Geider 1993). Thus, our assumption of constant $P_{m}^{C}$, although not correct, is also not greatly at odds with available data.

Third, we assumed that $P_{n l}^{C}$ was independent of day length. This assumption appears to hold for the diatom Skeletonema costatum (Gilstad et al. 1993), although it is not generally valid. For example, cell-specific lightsaturated photosynthesis $\left(P_{m}^{c e l l}\right)$ increased under short photoperiod in the diatom Thalassiosira weissflogii (Hobson et al. 1985). Consistent with the increase of $P_{m}^{r e l l}$ in $T$ weissflogii was a concurrent increase in the ratio of Rubisco to chl a (Hobson et al. 1985). In contrast, our model assumes that $P_{n i}^{<}$(and by implication the ratio of Rubisco to biomass) is independent of photoperiod. An error in this assumption should be reflected in departures of growth rate from a linear dependence on day length predicted by the model. In fact, such a departure is found in many microalgae (Brand \& Guillard 1981). A few studies allow examination of growth rate as a function of the day length in the range $6: 18$ to $18: 6 \mathrm{~h}$ light:dark cycles (Fig 6). Growth rate increases with day length, but the percentage increase in growth is often less than the percentage increase in day length. As noted above, Skeletonema costatum appears to be an exception to this generalization with $\mu$ proportional to day length (Yoder 1979 . Gilstad et al. 1993) 
Fourth, we note that the Arrhenius equation is an approximation of the temperature-dependence of growth rate that does not apply at temperatures near the upper and lower limits of the species (Li 1980). Many investigators assume an exponential dependence of growth rate on temperature (Eppley 1972 Geider 1987, Cloern et al. 1995). Alternatives to the Arrhenius equation have been discussed by Ahlgren (1987). Within the tolerance limits of a species, the temperature dependence of net growth rate arises from variation in both gross photosynthesis and respiration. It is likely that there are differences in the temperature dependent responses of photosynthesis and respiration. In principle, these responses can be incorporated into the model to provide greater fidelity in the region of the temperature optimum.

Fifth, the Monod equation is generally applied as a model of the substrate dependence of nutrient-limited growth rate. Unfortunately, there are few observations relating the nutrient-limited balanced growth rate to ambient nutrient concentration. This arises because of the low residual nutrient concentrations observed over a wide range of relative growth rates in nitrogen-and phosphorus-limited chemostat cultures. Significantly, the half saturation constant, $K_{N}$, appears to be independent of temperature (Ahlgren 1987). This supports our treatment of the effects of temperature and nutrient availability as multiplicative (see Eq. 12).

Finally, we note that the steady-state model does not resolve variations of $\theta$ that may occur with time of day. There is limited and conflicting data on the diel variations of $\theta$. One might expect $\theta$ to have minimum values at the end of the light period (due to accumulation of carbohydrate energy reserves during the day) and maximum values at the end of the dark period (due to consumption of these energy reserves and continued chl a synthesis at night). This appears to be the case in some cyanobacteria growing under nutrient-limited conditions or at light saturation. However, the diel variability in $\theta$ is often $<20 \%$ (van Liere et al. 1979, Foy \& Smith 1980). Kohata \& Wantanabe (1989) found that $\theta$ varied by about $30 \%$ (increasing during dark period) in Pyramimonas parkeae grown on a 12:12 h light:dark cycle. Stramski \& Reynolds (1993) found that $\theta$ ranged from about 0.033 to $0.066 \mathrm{~g} \mathrm{~g}^{-1}$ over $4 \mathrm{~d}$ in Thalassiosira pseudonana exposed to natural variations in sunlight. Chl a:carbon was maximal just before dawn as expected, but the minimum values were observed in mid-morning, and there was considerable day-to-day variability (Stramski \& Reynolds 1993). In contrast, $\theta$ was found to be independent of time of day (mean = $0.018 \mathrm{~g} \mathrm{~g}^{-1}$ ) in Chattonella antiqua grown on 12:12 h light:dark period (Kohata \& Wantanabe 1988). Similarly, Cosper (1982) and Gilstad et al. (1993) observed little variability of $\theta$ with time of day for Skeletonema costatum grown on $12: 12$ h light:dark cycles at irradiances ranging from 15 to $1500 \mu \mathrm{mol}$ photons $\mathrm{m}^{-2} \mathrm{~s}^{-1}$ Thus, although chl a-specific PI parameters may show considerable diel variability, variations in $\theta$ are less pronounced.

\section{Relation of $\theta$ to $I_{k}$}

${ }^{14} \mathrm{C}$ labeling of particulate carbon, chl a and other pigments (Redalje \& Laws 1981, Goericke \& Welschmeyer 1992) and flow cytometric assessment of biomass and pigment content of single cells (Li et al. 1993, Campbell et al. 1994) provide 2 techniques for estimating $\theta$ directly in natural assemblages, although these approaches are not without technical difficulties. In this section we consider the possibility that commonly measured parameters of the photosynthesis-irradiance response curve may provide information on variability of $\theta$ in nature. We can rearrange Eq. (6) to obtain a relation between $\theta$ and $I_{k}$

$$
\theta=\frac{P_{m}^{C}}{\alpha^{c h l}} \frac{1}{I_{k}}=\frac{P_{m}^{C}}{P_{m}^{c h l}}
$$

Under nutrient replete conditions, $P_{m}^{C}$ and $\alpha^{c h l}$ are assumed to be constant and $\theta$ is predicted to be inversely related to $I_{k}$. Observations consistent with this relation are illustrated in Fig. 7. Support is also provided by observations that a 2 -fold decline of chl a per cell in Chlamydonomas reinhardtii between growth irradiances of 47 and $400 \mu \mathrm{mol}$ photons $\mathrm{m}^{-2} \mathrm{~s}^{-1}$ was accompanied by a 2 -fold increase in $I_{k}$ (Neale \& Melis 1986).

\section{Why do phytoplankton photoacclimate?}

Photoacclimation is often considered to allow phytoplankton to maximize growth rate under unfavorable conditions of low energy supply. In contrast, our model treats photoacclimation as the down regulation of pigment content under high irradiance. Our predictions of

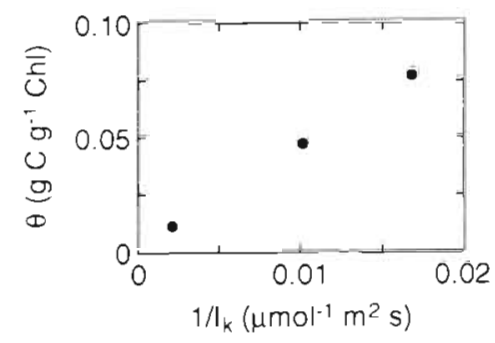

Fig. 7. Variation of the chl a:carbon ratio, $\theta$, with the irradiance parameter $I / I_{k}$, where $I$ is growth irradiance, in Thalassiosira pseudonana (Cullen \& Lewis 1988) 
the effect of acclimation to high irradiance on growth rate leads to the counter intuitive conclusion that photoacclimation reduces a cell's growth rate under low light without a corresponding increase in growth rate at light-saturation. This occurs in our model because $P_{m}^{c}$ was assumed to be constant. Thus, a reduction in pigment content $(\theta)$ results in a reduction in the carbon-specific rate of photosynthesis (i.e. $\alpha^{c h l} \theta n$ ) at low light, without affecting the carbon-specific rate of photosynthesis at light saturation.

Maximizing growth rate is not the only criterion for success in nature. Raven (1980) proposed 3 design criteria that must be considered in evaluating acclimation of the photosynthetic apparatus. These are (1) the cost of biosynthesis of the components of the photosynthetic apparatus, (2) the catalytic efficiency of these components, and (3) the susceptibility of these components to photoinhibitory damage. The first 2 criteria are implicit in our model. It is the third criterion that we invoke as a possible explanation for the reduction of $\theta$ prior to the light saturation of growth rate. Specifically, we hypothesize that down regulation of pigment content occurs as a means of reducing photoinhibitory damage (or the potential for photoinhibitory damage if cells are transiently exposed to high light). The observed dependence of $\theta$ and $\mu$ on irradiance supports our contention. Note that the decline in $\theta$ occurs at irradiances at which $\mu$ is still light-limited in Fig. 3. If it were possible for microalgae to maintain $\theta$ at the value $\theta_{m}$ at these intermediate irradiances, then we would expect $\mu$ to be higher at these irradiances. However, $\theta$ declines before $\mu$ becomes light-saturated indicating that some constraint other than maximizing light absorption is at work even under light-limiting conditions. It could also be argued that the less than 'optimal' behavior results from a deficiency of our model. For example, one could speculate that an increase of $P_{m}^{C}$ would arise during acclimation to high light from a re-allocation of photosynthate from synthesis of pigments to synthesis of Rubisco or ribosomal RNA. However, observations of the light dependence of $P_{m}^{c}$ do not support the speculated monotonic increase (Geider 1993).

\section{CONCLUSION}

Patterns in the light, nutrient and temperature dependencies of the chl a:carbon ratio of phytoplankton have been recognized for over 30 yr (Eppley \& Sloan 1966, Goldman 1980, Geider 1987, Langdon 1988b, Kiefer 1993). Both $I / K_{l}$ (where $K_{l}$ is the lightsaturation parameter for growth rate), and the relative growth rate $\left(\mu / \mu_{m}\right)$ have been recognized as scaling factors. Eqs. (5) and (11) summarize our scaling rules for chl a:carbon as a function of either irradiance or growth rate. These rules arise from a simple model of phytoplankton growth and acclimation that includes both an energy budget and an explicit statement of a rule for regulating pigment content. One conclusion is that adjustment of pigment levels in response to temperature and nutrient availability follows the same rule as adjustment of pigment levels to irradiance.

The available data are not sufficient to rigorously test the assumptions of our model. These include the assumption of constant chl a-specific initial slope of the photosynthesis-irradiance response curve (independent of growth temperature, irradiance or nutrient concentration), the assumption that temperature-and nutrient-limitation only enter through their effects on the carbon-specific light-saturated photosynthesis rate, and the assumption that respiration need not be explicitly considered. However, the curve-fitting exercises that we have undertaken indicate that the model can account for the systematic variability of growth rate and chl a:carbon ratio in response to irradiance, temperature, day length and nutrient-limited growth rate. The model suggests experiments that should be undertaken to refine our understanding of physiological responses of pigment content to the physical/chemical environment.

Oceanographers often relate chl a concentration to phytoplankton biomass using empirical factors. It has long been recognized that these factors lack precision. For example, Strickland (1960) concluded that the chl a:carbon ratio could not be estimated from environmental data (irradiance, nutrient concentration, temperature) to better than a factor of 0.3 to 3 , a point reiterated by Banse (1977). Despite success in describing growth and chl a content of monospecific cultures over a wide range of conditions, our model may not improve estimates of the chl a:carbon ratio $(\theta)$ of field populations because of the considerable interspecific variability in maximum growth rates, maximum chl a contents and light absorption characteristics of phytoplankton. However, it is likely that fundamental design criteria related to energetics and safety may preclude large departures of photosynthetic parameters and cell pigment content from simple regulatory rules. The model does, in any case, provide a framework for evaluating the potential importance of interspecific variability in photoacclimation to growth and primary productivity in the sea.

Finally, we note that knowledge of $\theta$ may not be as important as knowledge of the carbon-specific rate of light absorption $\left(a^{C}\right): a^{C}$ is the appropriate parameter for estimating phytoplankton biomass from ocean color, just as $a^{\text {chl }}$ is the appropriate parameter for estimating chl a concentration (by definition $a^{C}=a^{c h l} \theta$ ). It is largely because chl $a$ is the common currency of 
investigations into phytoplankton productivity and physiology that researchers have chosen to relate ocean color to chl a concentration. The ability to estimate biomass directly from light absorption would be advantageous. Although framed in terms of the chl a:carbon ratio $(\theta)$, our model employs $\theta$ as a proxy for the carbon-specific rate of light absorption and photosynthetic energy conversion. This arises from our assumption of constant initial slope of the PI curve. We recognize that chl a may not be the best or most appropriate index of the rate of light absorption (Sathyendranath et al. 1987). Although we can readily reformulate our model directly in terms of rates of light absorption and light-saturated photosynthesis, such a formulation cannot be tested with currently available data. It remains to be seen whether interspecific variability in the parameters of an absorption-based formulation of our model would be reduced relative to our current chl a-based version.

Acknowledgements. This work was supported by UK Natural Environment Research Council grant GR3/10222 (R.J.G), US National Science Foundation grants OCE-9301768 (R.J.G.) and OCE-9305896 (T.M.K.), and US Department of Energy Grant (93-01768 (R.J.G.).

\section{Appendix 1}

$$
\begin{gathered}
P^{C}=P_{m}^{C}\left[1-\exp \left(\frac{-\alpha^{c h l} I \theta}{P_{m}^{C}}\right)\right] \\
\frac{d c h l}{d t}=\rho_{c h l} P^{C} C-R^{c h l} c h l \\
\frac{d C}{d t}=\left(P^{C}-R^{C}\right) C=\mu C \\
\rho_{c h l}=k_{c h l} \frac{P^{C} C}{\alpha^{c h l} l c h l}=k_{c h l} \frac{P^{C h l}}{\alpha^{c h l} I \theta}
\end{gathered}
$$

where $k_{\mathrm{chl}}$ is the maximum proportion of photosynthesis that can be directed to chl a synthesis. Noting that

$$
\frac{d c h l / C}{d t}=\frac{1}{C} \frac{d c h l}{d t}-\frac{c h l}{C^{2}} \frac{d C}{d t}
$$

and that in balanced growth $d(c h l / C) / d t=0$, we obtain

$$
\frac{1}{C} \frac{d c h l}{d t}=\frac{c h l}{C^{2}} \frac{d C}{d t} \text {. }
$$

For the condition of balanced growth, substituting Eqs (A2) and (A3) into (A6) yields:

$$
\frac{C h l}{C}=\theta=\rho_{c h i} \frac{p^{C}}{P^{C}-R^{C}+R^{c h l}}
$$

Consider the case $R^{C}=R^{c h l}$, for which Eq. (A7) reduces to

$$
\theta=\rho_{c h l}
$$

Substituting Eq. (A4) into (A8) and rearranging yields

$$
\theta^{2}=k_{c h l} \frac{p^{c}}{\alpha^{c h i} I}
$$

Substituting Eq. (A1) into (A9) yields

$$
\theta^{2}=k_{c h l} \frac{P_{m}^{C}\left[1-\exp \left(\frac{-\alpha^{c h l} I \theta}{P_{m l}^{C}}\right)\right]}{\alpha^{c h l} I}
$$

Let

$$
a=\frac{P_{m}^{c}}{\alpha^{c h l} I}
$$

Substituting Eq. (A.11) into (A10) yields

$$
\theta^{2}=k_{\text {ch }} a\left[1-\exp \left(-\frac{\theta}{\alpha^{\text {chl } I}}\right)\right]
$$

For small values of the ratio for $\theta / a$, $\exp (-\theta / a)$ can be approximated as the first 3 terms of a Taylor series:

$$
\exp \left(\frac{-\theta}{a}\right)=1-\frac{\theta}{a}+\frac{\theta^{2}}{2 a^{2}}
$$

Substituting Eq. (A13) into (A12) and rearranging yields:

$$
\theta=\theta_{m} \frac{1}{1+\frac{\theta_{m} \alpha^{c h l} I}{2 P_{m}^{C}}}
$$

Note that under this condition, $k_{c h l}=\theta_{m}$

$$
\theta=\theta_{m} \frac{1}{1+\frac{\theta_{m} \alpha^{c h l} I}{2 P_{m}^{C}}}
$$

Alternatively, consider the case $R^{c h l}=0$ and $R_{\Gamma}=\zeta \mu$, for which Eq. (A7) becomes

$$
\begin{gathered}
\theta=\rho_{c h l}(1+\zeta) \\
\theta^{2}=k_{c h l} \frac{(1+\zeta) P_{f l}^{c}}{\alpha^{c h l} I} \\
\theta=\frac{k_{c h l}(1+\zeta)}{1+\frac{k_{c h l}(1+\zeta) \alpha^{c h l} I}{2 P_{r f l}^{C}}}
\end{gathered}
$$

Under this condition, we can set $k_{c h l}(1+\zeta)=\theta_{m}$, and thus we obtain a result identical to Eq. A15. In summary, Eq. (A15) describes the dependence of the chl a:carbon ratio on irradiance under conditions of balanced growth with either $R^{c h l}=0$ (no chl a degradation) or $R^{c h l}=R^{C}=\mu \zeta$ (chl a degradation has the same dependence on growth rate as cellular respiration). The Taylor series approximation (Eq. A 13) holds for values of $\theta / a<1$ (i.e. for $l / I_{k}<1$ ). However, we found that the approximation described the data well even at higher irradiances. 


\section{Appendix 2}

The dynamic model of photoadaptation of Geider et al. (1996) is identical in basic design and assumptions to the model presented in this paper. However, Geider et al. (1996) dealt in abstract quantities such as the pool of lightharvesting components $(L)$ and the pool of biosynthetic components $(E)$. The model presented in this paper is formulated in terms of readuly measured quantities, namely chl a concentration and organic carbon concentration. Equivalence between the Geider et al. (1996) treatment and this treatment can be achieved by noting the following equalities

Geider et al. (1996) This treatment

$P_{n}^{E} E / C$
$(L / C)(c h l / L)$
$k_{L}$ chl/L
$\sigma(c h l / L)$

$p_{m}^{c}$
$\theta$
$\theta_{m}$
$\alpha^{c h l}$

\section{LITERATURE CITED}

Ahlgren C (1987) Temperature functions in biology and their application to algal growth constants. Oikos 49:177-190

Banse K (1977) Determining the carbon-to-chlorophyll ratio of natural phytoplankton. Mar Biol 41:199-212

Berner T, Dubinsky Z, Wyman K, Falkowski PG (1989) Photoadaptation and the 'package' effect in Dunaliella tertiolecta (Chlorophyceae). J Phycol 25:70-78

Brand LE, Guillard RRL (1981) The effects of continuous light and light intensity on the reproduction rates of twenty-two species of marine phytoplankton. J Exp Mar Biol Ecol 50: $119-132$

Campbell L, Nolla HA, Vaulot D (1994) The importance of Prochlorococcus to community structure in the central North Pacific Ocean. Limnol Oceanogr 39:954-961

Chan AT (1978) Comparative physiological study of marine diatoms and dinoflagellates in relation to irradiance and cell size. 1 Growth under continuous light. J Phycol 14: $396-402$

Cloern JE, Grenz C, Vidergar-Lucas L (1995) An empirical model of the phytoplankton chlorophyll:carbon ratio - the conversion between productivity and growth. Limnol Oceanogr 7:1310-1313

Cosper E (1982) lnfluence of light intensity on diel variations in rates of growth, respiration and organic release of a marine diatom: comparison of diurnally constant and fluctuating light. J Plankton Res 4:705-724

Cullen JJ (1982) The deep chlorophyll maximum layer: comparing vertical profiles of chlorophyll a. Can J Fish Aquat Sci 39:791-803.

Cullen JJ, Lewis MR (1988) The kinetics of algal photoadaptation in the context of vertical mixing. J Plankton Res 10 : $1039-1063$

Eppley RW (1972) Temperature and phytoplankton growth in the sea. Fish Bull 70:1063-1085

Eppley RW, Sloan PR (1966) Growth rates of marine phytoplankton: correlation with light absorption by cell chlorophyll a. Physiol Plant 19:47-59

Escoubas JM, Lomas M, La Roche J, Falkowski PG (1995) Light intensity regulation of $C A B$ gene transcription is signaled by the redox state of the plastoquinone pool. Proc Natl Acad Sci 92:10237-10241
Falkowski PG, Dubinsky Z, Wyman K (1985) Growth-irradiance relationships in phytoplankton. Limnol Oceanogr 30 : $311-321$

Falkowski PG, Kiefer, DA (1985) Chlorophyll a fluorescence in phytoplankton: relationship to photosynthesis and biomass. J Plankton Res 7:715-731

Falkowski PG, La Roche J (1991) Acclimation to spectral irradiance in algae. J Phycol 27:8-14

Foy RH, Smith RV (1980) The role of carbohydrate accumulation in the growth of planktonic Oscillatoria species. $\mathrm{Br}$ Phycol J 15:139-150

Geider RJ 1984 Light and nutrient effects on algal physiology. PhD dissertation, Dalhousie University, Halifax, NS

Geider RJ (1987) Light and temperature dependence of the carbon to chlorophyll ratio in microalgae and cyanobacteria: implications for physiology and growth of phytoplankton. New Phytol 106:1-34

Gelder RJ (1992) Respiration: taxation without representation. In: Falkowski PG, Woodhead AD (eds) Primary productivity and biogeochemical cycles in the sea. Plenum Press, New York, p 333-360

Geider RJ (1993) Quantitative phytoplankton ecophysiology: implications for primary production and phytoplankton growth. ICES Mar Sci Symp 197:52-62

Geider RJ, Macintyre HL, Kana TM (1996) A dynamic model of photoadaptation in phytoplankton. Limnol Oceanogr 41:1-15

Geider RJ, Osborne BA, Raven JA (1985) Light dependence of growth and photosynthesis in Phaeodactylum tricornutum (Bacillanophyceae). J Phycol 21:609-619

Geider RJ, Platt T (1986) A mechanistic model of photoadaptation in microalgae. Mar Ecol Prog Ser 30:85-92

Gilstad M. Johnsen G, Sakshaug E (1993) Photosynthetic parameters, pigment composition and respiration rates of the marine diatom Skeletonema costatum in continuous light and a 12:12 h light-dark cycle. J Plankton Res 15: 939-951

Goericke R, Welschmeyer NA (1992) Pigment turnover in the manne diatom Thalassiosira weissilogii. I. The ${ }^{14} \mathrm{CO}_{2}$ labeling kinetics of chlorophyll a. J Phycol 28:498-507

Goldman JC (1980) Physiological processes, nutrient availability, and the concept of relative growth rate in marine phytoplankton ecology. In: Falkowski PG (ed) Primary productivity in the sea. Plenum Press, New York, p 179-193

Harding LW Jr (1994) Long-term trends in the distribution of phytoplankton in Chesapeake Bay: roles of light, nutrients and streamflow. Mar Ecol Prog Ser 104:267-291

Harvey HW (1934) Measurement of phytoplankton population. J Mar Biol Ass UK 19:775-792

Herzig R, Falkowski PG (1989) Nitrogen limitation in Isochrysis galbana (Haptophyceae) I. Photosynthetic energy conversion and growth efficiencies. J Phycol 25:462-471

Hobson LA, Morris WJ, Guest KP (198.5) Varying photoperiod, ribulose 1,5-bisphosphate carboxylase/oxygenase and $\mathrm{CO}_{2}$ uptake in Thalassiosira fluviatllis (Bacillariophyceae). Plant Physiol 79:833-837

Jassby AD, Platt T (1976) Mathematical formulation of the relationships between photosynthesis and light for phytoplankton. Limnol Oceanogr 21:540-547

Kana TM, Glibert PM (1987a) Effect of irradiances up to $2000 \mu \mathrm{E} \mathrm{m}^{-2} \mathrm{~s}^{-1}$ on marine Synechococcus WH7803-I. Growth, pigmentation, and cell composition. Deep Sea Res 34:479-495

Kana TM. Glibert PM (1987b) Effect of irradiances up to $2000 \mu \mathrm{E} \mathrm{m}^{-2} \mathrm{~s}^{-1}$ on marine Synechococcus WH7803- II. Photosynthetic responses and mechanisms. Deep Sea Res $34: 497-516$ 
Kiefer DA (1993) Modelling growth and light absorption in the marine diatom Skeletonema costatum. In: Evans GT, Fasham MJR (eds) Towards a model of ocean brogeochemical processes. Sprnger-Verlag, Berlin, p 91-121.

Kolber Z, Zehr J, Falkowski PG (1988) Effects of growth irradiance and nitrogen-limitation on photosynthetic energy conversion in photosystem II. Plant Physiol 88: $923-929$

Kohata K. Wantanabe M (1988) Diel changes in the composition of photosynthetic pigments and cellular carbon and nitrogen in Chattonella antiqua (Raphidophyceae). J Phy$\operatorname{col} 24: 58-66$

Kohata K, Wantanabe M (1989) Diel changes in the composition of photosynthetic pigments and cellular carbon and nitrogen in Pyramimonas parkeae (Prasinophyceae) J Phycol 25:377-385

Langdon C (1988a) On the causes of interspecific differences in the growth-irradiance relationship for phytoplankton. I. A comparative study of the growth-irradiance relationship of three marine phytoplankton species: Skeletonema costatum, Olisthodiscus luteus and Gonyaulax tamarensis. J Plankton Res 10:1.291-1312

Langdon C (1988b) On the causes of interspecific differences in the growth-irradiance relationship for phytoplankton. II. A general review. J Plankton Res 10:1291-1.312

Laws EA, Bannister TT (1980) Nutrient- and light-limited growth of Thalassiosira fluvialtilis in continuous culture, with implications for phytoplankton growth in the ocean. Limnol Oceanogr 25:457-473

Lewis MR (1992) satellite ocean color observations of global biogeochemical cycles. In: Falkowskı PG, Woodhead AS (eds) Primary productivity and biogeochemical cycles in the sea. Plenum Press, New York, p 139-153

Ll WKW (1980) Temperature adaptation in phytoplankton cellular and photosynthetic characteristics. In: Falkowski PG (ed) Primary productivity in the sea. Plenum Press, New York, p 259-279

Li WKW, Zohary T, Yacobi YZ, Wood AM (1993) Ultraphytoplankton in the eastern Mediterranean Sea: towards deriving phytoplankton biomass from flow cytometric measurements of abundance, fluorescence and light scatter. Mar Ecol Prog Ser 102:79-87

Longhurst A, Sathyendranath S, Platt T, Caverhill C (1995) An estimate of global primary production in the ocean from satellite radiometer data. J Plankton Res 17:1245-1271

Maxwell DP, Falk S, Trick CG, Huner NPA (1994) Growth at low temperature mimics high-light acclimation in Chlorella vulgaris. Plant Physiol 105:535-543

Mills E (1989) Biological oceanography: an early history. Cornell University Press, Ithaca

Morel FMM (1987) Kinetics of uptake and growth in phytoplankton. J Phycol 23:137-150

Muggli DL, Harrison PJ (1996) Effects of nitrogen source on the physiology and metal nutrition of Emilania huxleyi grown under different iron and light conditions. Mar Ecol Prog Ser 130:255-267

Neale PJ, Melis A (1986) Algal photosynthetic membrane complexes and the photosynthesis-irradiance curve: a comparison of light-adaptation responses in Chlamydomonas reinhardtii (Chlorophyta). J Phycol 22:531-538

This article was submitted to the editor
Nielsen MV (1992) Irradiance and daylength effects on growth and chemical composition of Gyrodinum aureolum Hulburt in culture. J Plankton Res 14:811-820

Nielsen MV (1996) Growth and chemical composition of the toxic dinoflagellate Gymnodinium galatheanum in relation to irradiance, temperature and salinity. Mar Ecol Prog Ser 136:205-211

Paasche E (1967) Marine plankton algae grown with light-dark cycles. I. Coccolithus huxleyl. Physiol Plant 20: 946-956

Paasche E (1968) Marine plankton algae grown with light-dark cycles. II. Ditylum brightwellii and Nitzschia turgıdula. Physiol Plant 20:946-956

Penning de Vries FWT, Brunsting AHM, van Laar HH (1974) Products, requirements and efficiency of biosynthesis: a quantitative approach. J Theor Biol 45:339-377

Post AF, Loogman JG, Mur LR (1985) Regulation of growth and photosynthesis by Oscillatoria agardhii grown with a light/dark cycle. FEMS Microbiol Ecol 31:97-102

Raps S, Wyman K, Siegelman HW, Falkowski PG (1983) Adaptation of the cyanobacterium Microcystis aeruginosa to light intensity. Plant Physiol 72:829-832

Raven JA (1980) Chloroplasts of eukaryotic micro-organisms. In: Gooday GW, Lloyd D, Trinci APJ (eds) The eukaryotic microbial cell. Society for General Microbiology Symposium 30. Cambridge University Press, Cambridge, p 181-205

Redalje DG, Laws EA (1981) A new method for estimating phytoplankton growth rates and carbon biomass. Mar Biol 62:73-79

Rivkin RB, Seliger HH, Swift E, Biggley WH (1982) Lightshade adaptation by the oceanic dinoflagellates Pyrocystis noctiluca and $P$. fusiformis. Mar Biol 68:181-191

Sakshaug E, Andersen K, Kiefer DA (1989) A steadystate description of growth and light absorption in the marine planktonic diatom Skeletonema costatum. Limnol Oceanogr 34:198-205

Sathyendranath S, Lazzara L, Prieur L (1987) Variations in the spectral values of specific absorption of phytoplankton. Limnol Oceanogr 32:403-415

Stramski D, Reynolds . RA (1993) Diel variations in the opt.cal properties of a marine diatom. Limnol Oceanogr 38 $1347-1364$

Strickland JDH (1960) Measuring the production of marine phytoplankton. Bull Fish Res Bd Canada 122:1-172

Sukenik A, Bennett J, Falkowski P (1987) Light-saturated photosynthesis-limitation by electron transport or carbon fixation? Biochim Biophys Acta 891:205-215

Terry KL, Hirata J, Laws EA (1983) Light-limited growth of two strains of the marine diatom Phaeodactylum tricornutum Bohlin: chemical composition, carbon partitioning and diel periodicity of physiological processes. J Exp Mar Biol Ecol 68:209-227

van Liere L, Mur RL, Gibson CE, Herdman M (1979) Growth and physiology of Oscillatoria agardhii Gamont cultivated in continuous cultures with a light-dark cycle. Arch Microbiol 123:315-318

Yoder JA (1979) Effect of temperature on light-limited growth and chemical composition of Skeletonema costatum (Bacillariophvceae). J Phycol 15:362-370

Manuscript first received: September 9, 1996

Revised version accepted: January 16, 1997 